Disponível em

http://www.anpad.org.br/rac

RAC, Curitiba, v. 14, n. 2, pp. 353-359, Mar./Abr. 2010

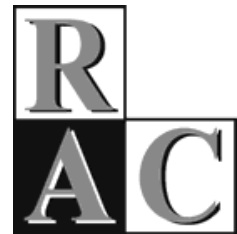

Documentos e Debates:

\title{
Documento - Sobre Maestria, Profissionalização e Artesanato Intelectual
}

\author{
Concerning Mastery, Professionalization and Intellectual Craftsmanship
}

* Endereço: Tânia Fischer

Universidade Federal da Bahia, Escola de Administração, Núcleo de Estudos sobre o Poder e Organizações Locais, Av. Reitor Miguel Calmon, s/n, $3^{\circ}$ andar, Vale do Canela, Salvador/BA, 40110-903. E-mail: nepol@ufba.br

Copyright (C) 2010 RAC. Todos os direitos, inclusive de tradução, são reservados. É permitido citar parte de artigos sem autorização prévia desde que seja identificada a fonte. 


\section{UM CONVITE IRRECUSÁVEL}

O convite para o debate do mestrado profissional é irrecusável porque, em primeiro lugar, é feito pelo professor Jaime Fensterseifer, de tão altas credenciais acadêmicas e um dos raros membros de nossa academia que valoriza indiscutivelmente o saber prático. Tendo incorporado ao seu brilhante currículo uma formação tecnológica que o habilita a produzir bons vinhos, sabe-se que o seu trabalho de conclusão de curso [TCC] tecnológico nesta área foi aplaudido pela banca examinadora, o que pode ser considerado como aprovação com louvor.

No início dos anos 90, participei da primeira comissão, instituída pela Coordenação de Aperfeiçoamento de Pessoal de Nível Superior [CAPES], que propôs o mestrado profissional. Esta comissão era integrada por seis acadêmicos e dois representantes dos setores produtivos. Após quase um ano de discussões, produziu-se o documento "Mestrado no Brasil: a situação e uma nova perspectiva”, que resultou, posteriormente, na Portaria Normativa n. 47 de 17 de outubro de 1995.

Dando um corte no tempo, em 2008 foi constituída nova comissão multidisciplinar para discutir o mestrado profissional, da qual fez parte o professor Jaime Fensterseifer, representando a área de Ciências Sociais Aplicadas.

Há, neste momento, nova polêmica sobre o mestrado profissional. De um lado, tem-se o Ministério de Educação, compreendendo a CAPES e o Conselho Nacional de Educação regulamentando a oferta de cursos de mestrado profissional, dispondo-se a fomentar cursos novos. De outro, a comunidade acadêmica permanece dividida entre as áreas que oferecem o mestrado profissional e as que reagem a ele, como tradicionalmente as áreas de educação e direito.

O grupo de programas de mestrado profissional criou o Fórum Nacional dos Mestrados Profissionais, instituído como entidade permanente em 2009, após quatro eventos nacionais, tendo a conformação inicial de uma associação de programas. Na quinta reunião anual deste fórum, foi aprovado um regimento interno que propõe um fórum nacional de coordenadores de programas de mestrado profissional voltado para a articulação e proposição de políticas acadêmicas tecnológicas, de inovação de inserção social comprometidas com "a formação de profissionais para o desenvolvimento de novas tecnologias; e aperfeiçoamento de processos e produtos, contribuindo para a capacidade técnica e científica e para o atendimento das demandas geradas pelo mercado de trabalho" (Fórum dos Mestrados Profissionais, 2009, p. 1). Liderado principalmente pelas áreas de Engenharia, Saúde e Multidisciplinar, tendo até mesmo representações dos mestrados de ensino de Ciências (Física, Química e Matemática), é de se questionar por que a participação de coordenadores de programas de Administração é tão pouco expressiva no fórum. Talvez porque a área de Administração registre 30 mestrados profissionais em um total de 105 programas e cursos (CAPES, 2009). Outra hipótese é a de que essa é uma área com desenhos bastante tradicionais de ensino em seus cursos acadêmicos.

Em mestrado profissional, a prática acadêmica é desafio. Imaginar, criar e desenvolver cursos inovadores em sistema fortemente regulado, com fortes componentes isomórficos com as áreas tradicionais de ciência (que são o paradigma para todas as demais) se constitui de fato em grande desafio. Neste ponto do debate, recorro a uma experiência que é a segunda razão para aceitar o convite, ou seja, a vivência da história recente do mestrado profissional desde a sua concepção, no início da década de 90 até a posterior coordenação de uma das primeiras experiências de mestrado profissional em Administração. 


\section{A EXPERIÊnCia do Mestrado Multidisciplinar e Profissional em DesenVolvimento e GESTÃo SOCIAL}

Coordeno, desde 2000, o Programa de Desenvolvimento e Gestão Social [PDGS] apoiado pelo Fundo Verde Amarelo/MCT, cujas ações resultaram na implantação de um conjunto de cursos de caráter experimental: um curso de extensão em 2002, especialização presencial e a distância em 2004 e o mestrado profissional em 2006. Pela primeira vez um programa de pós-graduação lato e stricto sensu deu origem a uma graduação tecnológica que se iniciou em 2009 e no final deste mesmo ano registra a maior procura da Universidade. Segundo dados do Serviço de Seleção da UFBA, a procura é equivalente apenas ao curso de Medicina (34 candidatos/vaga).

Todos os cursos do PDGS exigem Residência Social [RS], ou imersão na prática profissional em programas, projetos e ações de desenvolvimento territorial. A RS foi premiada como tecnologia social pela FINEP e reconhecida como uma das inovações sociais de destaque em 2006 da Região Nordeste. Os alunos da RS são oriundos de oito Estados do país, de cinco outros países e de várias regiões da Bahia; são gestores de programas de desenvolvimento territorial, gestores de ONGs de diferentes níveis de governo, do sistema $\mathrm{S}$, de grandes empresas públicas e privadas com projetos de responsabilidade social, gestores da segurança pública, da saúde, programas sociais, lideranças religiosas católicas e evangélicas, entre outros. Enfim, um grupo multicultural, multiinstitucional de grande diversidade, mas convergente nas práticas de trabalho na gestão de diferentes escalas territoriais procuram o curso. Esta experiência de educação profissional em um programa que articula pós-graduação e graduação, e têm na graduação tecnológica e no mestrado profissional os cursos de maior procura e impacto social, tem sido uma construção artesanal coletiva, artesanato intelectual e prática pedagógica.

Como fez em 1997, a RAC abre espaço para a discussão do tema mestrado profissional. Neste texto, discute-se a proposta do mestrado profissional como estratégia de formação profissional, com natureza e estrutura próprias e não como curso referenciado pelo eixo acadêmico. Não é, portanto, um curso de qualidade menor e sim um curso diferente em essência, componente de um sistema de fluxo interconectado de ensino superior tecnológico, com articulações possíveis, entre cursos de graduação e pós-graduação. Este Programa compreendeu construção, desenvolvimento e avaliação de um modelo de ensino com articulação vertical entre cursos, com soluções educacionais compartilhadas entre eles e em processo de articulação entre instituições do Nordeste e do Sul do país para a utilização de tecnologias de informação e comunicação [TICs] e para intercâmbio de professores e alunos (Residência Social), especialmente na graduação tecnológica. Em se tratando de um programa cujo tema é Desenvolvimento e Gestão Social, ele é de natureza interdisciplinar e está compreendido em uma das áreas de litígio da Administração com outras áreas do conhecimento, especialmente a área multidisciplinar, ainda em reposicionamento nas agências de fomento e regulação no país. Estas tensões e dilemas tornam ainda mais instigante o desenvolvimento de um mestrado profissional como inovação em si mesmo, que requerem esforços de gestão coletiva e estão criando uma "comunidade de práticas” que se disseminaram pelo país. A difusão da Residência Social em outras universidades, a criação da Rede Pesquisadores em Gestão Social que se encontra anualmente (há 5 anos) no Encontro Nacional de Pesquisadores de Gestão Social [ENAPEGS], o incremento substancial de publicações na área visíveis nos Colóquios internacionais de Poder Local (e no próprio ENANPAD), nos indicam que o propósito inicial do Ministério de Ciência e Tecnologia, ao apoiar grupos inovadores em gestão com recursos do Fundo Verde-Amarelo, foi atingido. Mas, este é um programa em permanente construção; se considerando que a gestão social, enquanto área de conhecimentos e práticas, se renova com a mesma velocidade da dinâmica social a que se reporta, mantemos uma pesquisa de avaliação permanente do PDGS, com foco especial na graduação tecnológica e no mestrado profissional. As pesquisas sobre ensino profissional vêm quebrando as fronteiras entre a academia e as oficinas do mundo; estas encontram no mestrado profissional um interessante recorte para a inovação tecnológica, de caráter artesanal. Não ensinamos inovação e empreendedorismo? Vamos praticar o que ensinamos. 


\section{Mestrado Profissional e Artesanato Intelectual}

Usando a metáfora do artesanato recentemente recuperado por Sennett (2009), que retoma o conceito de artesanato intelectual utilizados por Charles Wright Mils, um curso de mestrado profissional pode ser considerado uma construção artesanal que requer artífices inquietos, máquinas e ferramentas estimulantes, resistência à ambigüidade e qualidade artesanal (Sennett, 2009), entre outras características do artesanato elencadas por Sennett (2009) e Mills (2009).

Não é preciso muito esforço para associarmos os artífices inquietos a nós, professores, máquinas e oficinas, aos espaços institucionais e equipamentos de que dispomos, ferramentas estimulantes às nossas estratégias de ensino e pesquisa, resistência à ambigüidade dos nossos embates internos e externos e qualidade artesanal do que gostaríamos de fazer e tentamos fazê-lo em nosso programas.

Especialmente em causas desafiadoras como é o mestrado profissional, os requisitos são muito simétricos ao fazer artesanal. O mestrado profissional remete à ideia de mestria e ofício, ao saber em uso e a espaços de aplicação do conhecimento. O movimento de reconstrução da pós-graduação retoma o mestrado profissional como estratégia de formação para os setores não acadêmicos. Este movimento encontra um sistema instituído com estruturas de formação acadêmicas voltadas à formação de professores para o ensino superior, com finalidades claramente voltadas à pesquisa e docência. Ora, cursos e currículos não são apenas grades ou projetos exclusivamente de caráter pedagógico. São também arenas de interesse especialmente considerando os embates entre a dedicação ao ensino e a pesquisa, entre produção acadêmica e gestão universitária, entre docência e consultoria, entre comunidades acadêmicas entre si e destas com agências reguladoras do ensino e da pesquisa.

No inicio da pós-graduação, o Parecer n. 977 (1965) da CAPES definia o doutorado como o curso que promove a formação cientifica ou cultural ampla e aprofundada, desenvolvendo criatividade e capacidade de pesquisa. Já o mestrado foi caracterizado com a etapa preliminar de estudos para obtenção do grau de doutor e também como formação profissional avançada e terminal para os que desejassem seguir carreiras não acadêmicas. Como sabemos, o eixo acadêmico da pós-graduação, stricto sensu foi bastante reforçado, até mesmo porque o mestrado acadêmico foi, por um bom tempo, o curso dominante na estrutura da pós-graduação. Na área de administração, os cursos de especialização (MBAs) substituíram o mestrado profissional sem conferir o grau acadêmico, mas sendo um atrativo produto do mercado de ensino. A instituição do mestrado profissional em 1995 recupera a proposta já contida no Parecer Sucupira e encontra um sistema fortemente orientado para a formação de professores e pesquisadores. Militamos em área que lida com suas ambiguidades e tensões de uma forma que já foi denominada "síndrome bipolar da pós-graduação brasileira" (Fischer, 2003, p. 24). Oscilando entre valores, padrões e critérios estritamente acadêmicos e as exigências de formação do mundo do trabalho, o mestrado profissional é a forma mais visível de disputas ideológicas entre áreas do conhecimento e entre lideranças acadêmicas que defendem tradições versus inovações, como se fossem excludentes, reforçando a inércia estrutural e a hipervalorização do eixo acadêmico. Nossas tradições burocráticas e ancestralidade cartorial, em sistema centralmente regulado, como é o da educação brasileira em geral e o da pós-graduação em particular, levam-nos a perguntar primeiro quais são as regras, antes de criar um desenho de curso, pois o sistema de avaliação que construímos, com mérito e pelo mérito, ostenta duas faces: estimula a qualidade e reprime a criatividade e a inovação, atributos fundamentais de processos artesanais, dos quais o mestrado profissional é exemplo pleno de significado.

Vivemos a valorização da educação profissional; o mestrado, conforme definido por portaria normativa do CAPES, é uma estratégia de formação de avaliação no novo ciclo desenvolvimentista que experimentamos. 


\section{Educação Profissional e o Novo Contexto de DesenVolvimento}

A Portaria Normativa n. 7 (2009), que dispõe sobre o mestrado profissional no âmbito da Coordenação de Aperfeiçoamento de Nível Superior [CAPES], é assinada pelo Ministério da Educação e institui; como política de governo, o mestrado profissional, delegando à Capes a "regulação de oferta mediante chamadas públicas"” (Lei n. 10.172, 2001, art.10) bem como a avaliação dos cursos oferecidos. Pela primeira vez, desde a instituição do mestrado profissional pela Portaria Normativa n. 47 (1995) da CAPES, e a subseqüente regulamentação feita pela Portaria n. 80 (1998) de 1998, também da CAPES, o Ministério de Educação chama diretamente a si, como poder executivo, a decisão sobre a oferta e a regulação de mestrados profissionais.

Que pode significar esta realocação de poderes? Algumas hipóteses podem ser levantadas sobre o novo cenário institucional. Vive-se, na verdade, um momento de transformações significativas no ensino brasileiro em todos os níveis; entre outras mudanças que sinalizam uma reforma de ensino que não diz seu nome, mas que ocorre no aumento de vagas nas universidades públicas, na contratação de número significativo de professores e funcionários, na expansão do ensino a distância e nas políticas de formação de professores para todos os níveis de ensino, conforme está expresso no V Plano Nacional de Pós-Graduação e o que interessa diretamente ao tema deste texto: a ênfase na formação profissional.

O Plano de Desenvolvimento da Educação (2007) compreende políticas e ações interligadas em todos os níveis de ensino. O Brasil Profissionalizante, Decreto n. 6.302 (2007), ratifica a política de apoio à profissionalização, o que se concretiza com a transformação dos Centros Federais de Educação Tecnológica [CEFETs] em Institutos Federais de Educação [IFETs], possibilitando a abertura de cursos superiores de graduação e pós-graduação a estas instituições remanescentes, em sua maioria escolas técnicas e agrotécnicas de $2^{\circ}$ grau. Serão abertas 190 mil vagas em educação tecnológica, sendo investido R\$ 1,1 bilhão de 2008 a 2011. Os 168 institutos estão presentes em 26 Estados e no Distrito Federal (Ministério da Educação, 2009). Ora, se a política de apoio à educação profissional é afirmativa a este ponto, não é de surpreender que a portaria normativa tenha sido considerada a expressão de uma política de Estado, que retoma o apoio à formação profissional expresso no parecer que institui a pós-graduação brasileira. O desenvolvimento territorial é o epicentro de programas governamentais no novo ciclo desenvolvimentista que vive o Brasil, caracterizado pelos programas de renda mínima, e correção de assimetrias sociais, pelos projetos de infraestrutura que reconfiguram territórios, pela emergência de novos pólos de desenvolvimento nas regiões norte, centro-oeste e nordeste. O governo renova quadros, o setor de serviços ampliou-se e o Brasil é escolhido para a sede de eventos que catalisam a reestruturação de cidades e regiões, como as Olimpíadas e a Copa.

Atualmente, os investimentos em formação de quadros para os setores produtivos na indústria, serviços em geral, e governos em todos os níveis em particular, são componentes dos programas de desenvolvimento de territórios de cidadania de mesorregiões e de aceleração do crescimento, entre outros. São necessários mais e melhores profissionais e o sistema de ensino brasileiro deve dar respostas estratégicas. O mestrado profissional pode ser uma delas. Como somos orientados por documentos legais em nossos processos de artesanato intelectual, no que se refere ao ensino, parece interessante identificar os possíveis pontos de tensão e dilemas que a última portaria ministerial está trazendo ao mestrado profissional.

\section{Dilemas e Tensões: Mestrados Profissionais}

A Portaria Normativa n. 7 (2009) é bem mais enfática do que as regulamentações anteriores na natureza diferenciada do Mestrado Profissional, falando "na especificidade do conhecimento científico e tecnológico a ser produzido e reproduzido". Os objetivos expressos na portaria remetem diretamente 
à formação profissional, tais como: (1) a capacitação de profissionais para exercício de práticas avançadas e transformadoras; (2) a transferência de conhecimentos para a sociedade; (3) a articulação de formação profissional com entidades demandantes, promovendo eficiência e eficácia; (4) a agregação de competitividade e produtividade em empresas, organizações públicas e privadas, conferindo operacionalidade e organicidade ao conhecimento cientifico.

Quanto aos requisitos curriculares que se seguem na portaria, não há pontos de discordância evidentes nos debates sobre o tema, definindo-se que a proposta: deveria apresentar estrutura curricular objetiva, coerente com as finalidades do curso e consistentemente vinculada à sua especialidade, enfatizando a articulação entre conhecimento atualizado, domínio de metodologia pertinente à aplicação orientada para o campo de atuação profissional. Há mais sete requisitos do curso; a) como tempo de titulação; b) inclusão de atividades curriculares complementares; c) conciliação de perfil ao curso; d) equilíbrio no corpo docente entre doutores, profissionais e técnicos; e) comparação de carga horária docente e condição de trabalho compatíveis com o curso, sendo possível o tempo parcial; f) defesa apropriada do aluno do trabalho final que revele capacidade plena de expressão sobre o tema; g) exigência de trabalho final. Dois pontos de tensão são destacados: a composição do corpo docente e o trabalho de conclusão final. Ao colocar como requisito do curso a composição equilibrada do corpo docente integrado por doutores, profissionais e técnicos com experiência, criou-se uma zona cinzenta de critérios percebidos diferentemente por representações das distintas comunidades acadêmicas e agências reguladoras da validade da inclusão de profissionais não titulados nos cursos em face dos doutores com e sem experiência profissional. Não é questão simples. Por que não integrar em um corpo docente os praticantes, dividindo disciplinas e participando de bancas que preservem o poder de julgamento dos doutores, e integrando conselhos consultivos ou mesmo deliberativos de cursos, desde que se resguarde a proporcionalidade que não prejudique o curso, como atividade acadêmica que é? Por que não valorizar doutores com experiência profissional, atraindo os doutores que atuam fora da academia para atuar no ensino e na orientação com possibilidades de estabelecer pontes entre o mundo universitário e outros setores produtivos?

Quanto ao trabalho final, o parecer abre muitas possibilidades e esta flexibilidade incrementa bastante as resistências ao modelo profissional. Os diferentes produtos sugeridos pelo parecer são, na quase totalidade, exemplos de produção tecnológica que a área de Administração tem dificuldade de definir como tal. A Administração, área socialmente aplicada conforme a tabela de áreas de conhecimento das agências reguladoras da pesquisa e ensino de pós-graduação, é uma área jovem no Brasil e tenta afirmar-se como área de conhecimento e de produção intelectual relevante. No entanto, está agora desafiada a se integrar no novo ciclo de desenvolvimento nacional, aderindo à educação profissional pela via do mestrado profissional.

Nos documentos produzidos pelo Fórum de Pró-Reitores [FOPROP] e Fórum de Coordenadores de Mestrado Profissional identificam-se outros pontos de resistência. O FOPROP destaca como pontos críticos a avaliação dos programas e a sustentabildade financeira, o que é corroborado pelo Fórum Nacional dos Mestrados Profissionais. A polêmica sobre a participação de profissionais nos comitês de avaliação da CAPES está instaurada, mas há convergência quanto à separação entre os processos de avaliação (acadêmica e profissional). Quanto à sustentabildade, é um problema não resolvido. Por que os mestrados profissionais não podem ser oferecidos gratuitamente por universidades públicas com financiamento similar ao acadêmico ou por fundos especiais, como os fundos de pesquisa? A associação entre mestrados profissionais e empresas é um vício de origem, que deve ser superado, pois se renovam quadros governamentais e o novo ciclo desenvolvimentista que experimentamos vai requerer profissionais que atuem na gestão de empresas, nas diferentes esferas governamentais e no mundo associativo, mas principalmente, nas conexões entre estes mundos do trabalho em projetos que articulam os campos do saber e práticas de distintas origens e naturezas. 


\section{AMPLIANDO UM CONVITE}

Conclui-se este texto com um convite à comunidade para que os mestrados profissionais tenham tratamento artesanal no que isso significa de mais autêntico: a criação, o desenvolvimento e a validação de modelos de ensino que incorporam a luz que ilumina as práticas. Os estudantes que nos procuram com experiência de gestão (ou ainda sem tal experiência) buscam na academia a teoria que dê a ancoragem para as boas práticas essencialmente reflexivas.

Provavelmente já sabemos formar pesquisadores e talvez bons professores. De certa forma, o espelho do que pensamos ser e as vezes somos. Mais desafiador e mais interessante é formar profissionais para o mundo do trabalho nestes novos tempos que resgatam ideais desenvolvimentistas.

\section{REFERÊNCIAS BIBLIOGRÁFICAS}

Coordenação de Aperfeiçoamento de Pessoal de Nível Superior. (2009). Relação de cursos recomendados e reconhecidos. Ministério da Educação. Recuperado em 30 Outubro, 2009, de http://conteudoweb.capes.gov.br/conteudoweb/ProjetoRelacaoCursosServlet?acao=pesquisarGrandeArea

Decreto n. 6.302 de 12 de dezembro de 2007. (2007). Institui o Programa Brasil Profissionalizado. Recuperado em 30 outubro, 2009, de http://www.planalto.gov.br/ccivil_03/_Ato20072010/2007/Decreto/D6302.htm

Fischer, T. (2003). Seduções e riscos: a experiência do mestrado profissional. Revista de Administração de Empresas, 43(2), 119-123.

Fórum dos Mestrados Profissionais. (2009, outubro). Regimento interno do Fórum dos Mestrados Profissionais. Plenária do Encontro Nacional dos Mestrados Profissionais, Rio de Janeiro, RJ, Brasil, 5.

Lei n. 10.172 de 9 de Janeiro de 2001. (2001). Aprova o plano nacional de educação e dá outras providências. Recuperado em 30 outubro, 2009, de https://www.planalto.gov.br/ccivil_03/leis/leis_2001/110172.htm

Mills, C. W. (2009). Sobre o artesanato intelectual e outros ensaios. Rio de Janeiro: Zahar.

Ministério da Educação. (2009). A expansão da rede federal de educação profissional, científica e tecnológica . Recuperado em 30 outubro, 2009, de http://redefederal.mec.gov.br/index.php

Parecer n. 977 de 03 de dezembro de 1965. (1965). Definição dos cursos de pós-graduação. $\begin{array}{lllll}\text { Recuperado } & \text { em } & \text { outubro, } & 2009, & \text { de }\end{array}$ http://www.capes.gov.br/images/stories/download/legislacao/Parecer_CESU_977_1965.pdf

Plano de Desenvolvimento da Educação. (2007). Recuperado em 30 outubro, 2009, de http://pde.mec.gov.br/

Portaria Normativa n. 7 de 22 junho de 2009. (2009). Dispõe sobre o Mestrado Profissional no âmbito da Fundação Coordenação de Aperfeiçoamento de Pessoal de Nível Superior - CAPES. Recuperado em 30 outubro, 2009, de http://www.fnmp.org.br/documentos/portaria-normativamec-n07-22-06-2009/

Portaria Normativa n. 47 de 17 de outubro de 1995. (1995). Recuperado em 30 outubro, 2009, de http://www.fnmp.org.br/documentos/portaria-no-47-17-outubro-1995.pdf

Sennett, R. (2009). O artífice. São Paulo: RECORD.

RAC, Curitiba, v. 14, n. 2, pp. 353-359, Mar./Abr. 2010

www.anpad.org.br/rac 